\title{
Discriminative vs motivational interpretations of avoidance extinction: Extensions to learned helplessness
}

\author{
CYNTHIA SCHEUER and CARY O. SLTTON* \\ Florida Atlantic Liniersity. Boca Raton. Florida 33432
}

\begin{abstract}
Resistance to cxtinction of discriminated barpress avoidance in rats was assessed through the use of three procedures. each of which served to break the response-reinforcement contingency': classical extinction (CE). operant extinction $(O E)$. and a variable-ratio shock schedule ( $\left.V^{\prime} R\right)$. Greatest resistance to extinction was found for the VR group. followed by $\mathrm{OL}$ and then by $\mathrm{CL}$ Ss. thus supporting a discriminative rather than a motivational analysis. Reacquisition rates following extinction suggested evidence of "learned helplessness" in some Ss exposed to noncontingent CS-LS presentations.
\end{abstract}

Traditionally, the acquisition and maintenance of discriminated avoidance has been approached from the standpoint of motivational two-process theory. Within this framework. avoidance consists of (1) the classical conditioning of an emotional state through the continuous pairing of a CS with an aversive US and (2) escape from the CS (an operant component), a response maintained by the conditioned aversive properties of the CS. Extinction of avoidance is traditionally accomplished by the removal of shock, a procedure that operates directly on the emotional component $\left(R_{e}\right)$, thus indirectly affecting the avoidance response $\left(\mathrm{R}_{\mathrm{A}} \mathrm{V}\right)$ by decreasing the motivation to respond.

Recently. however. Rescorla and Skucy (1969) have supported a view that extinction of an operant can be accomplished by any condition that serves to disrupt the response-reinforcement relationship. Thus, any procedure that presents reinforcements independently of the S's behavior can be used to extinguish a conditioned operant.

This variation in extinction procedure has been extended to situations involving avoidance contingencies (Davenport \& Olsen. 1968: Coulson. Coulson. \& Gardner. 1970: Jackson \& Scheuer. 1972). but these studies have done little to determine the preference for motivational theory over a more parsimonious explanation of resistance to extinction. namely. the discrimination hypothesis (Mowrer \& Jones. 1945). This hypothesis explains such phenomena as the partial reinforcement effect, greater resistance to extinction following random as compared to single- or double-alternation schedules, and delayed as compared to immediate reinforcement (Lewis. 1960) in situations involving appetitive contingencies. Jackson and Scheuer (1972) have chosen to interpret their avoidance data in discriminative terms. although a motivational analy'sis 37916 . would be as applicable. They compared resistance to extinction of discriminated avoidance using the classical procedure involving CS.only presentations with one in which CS.US pairings occurred on every trial, regardless of the occurrence of the avoidance response. Coulson. Coulson. and Gardner (1970), in a nondiscriminative avoidance situation, compared extinction involving "playback" shock with the classical no-shock procedure. Although both sets of authors found least resistance to extinction under no-shock conditions, no clear choice can be made regarding the applicability of a motivational over a discriminative interpretation. Since the mere presence of shocks during extinction can serve either as a motivator or as a discriminative cue informing the $S$ it is still in a situation requiring avoidance, these data could as easily support either interpretation.

The present study permitted a direct test of the applicability of each theoretical interpretation as it applied to extinction of discriminated avoidance. Three different extinction procedures were employed. each of which served to break the response-reinforcement relationship. They were classical extinction (CE). involving presentations of the CS alone: operant extinction (OE), the presentation of CS-LS pairings on every trial, regardless of the occurrence of the avoidanco response: and a third procedure. variable-ratio shoch (VR). a condition in which shocks followed a random half of the CS presentations. Barpressing rather than shuttling was chosen in order to (1) minimize the involvement of classical components influencing $R_{A}$ v and (2) eliminate the influence of place and response-produced cues that might facilitate maintenance of the avoidance response.

A motivational analysis of avoidance extinction would predict greatest resistance to extinction using the OF procedure. since motivation is strengthened on each extinction trial: the CE: procedure should produce the fastest extinction. since the motivation to respond has been iompletely eliminated. Thus. according to motivational theor!. the higher the schedule of CS-LS 
pairings during extinction, the greater should be resistance to extinction of avoidance.

In contrast. an interpretation favoring the discrimination hypothesis would predict greatest resistance to extinction for VR Ss, since this condition is most similar to conditions occurring during acquisition, provided that the avoidance rate is less than $100 \%$. Thus, according to a discriminative interpretation, the more acquisition conditions resemble those of extinction, the greater will be resistance to extinction.

In addition, an attempt was made to determine if exposure to each of these extinction procedures had differential effects on the ability to reacquire the avoidance response. A discriminative interpretation would predict slowest relearning for VR Ss, since these animals would find most difficulty differentiating between one contingency and another, followed by $\mathrm{OE}$ (shock cue present) and, finally, by the CE Ss (shock cue absent). A strict motivational interpretation would predict fastest reacquisition by the $O E$ animals (maximum fear still present), followed by VR (partial extinction of fear), and slowest reacquisition for the CE Ss.

\section{METHOD}

\section{Subjects}

Fifteen (1\$) naive male albino rats, approximately 75 days of age at the start of preliminary training, served as $S$ s. They were maintained on ad lib food and water throughout all phases. except during initial barpress training.

\section{Apparatus}

The apparatus consisted of two modified Gerbrands operant conditioning chambers with Plexiglas front and rear walls. The units were housed within individual styrofoam chambers to cut down on extraneous visual cues. The manipulandum in each unit was a Gerbrands monkey lever, placed in the center of the front panel. $2 \frac{1 / 2}{2}$ in. above the grid floor. The CS was a jeweled amber 24-dc pilot light. mounted on the rear wall of the chamber 3 in. from the ceiling of the cage. Shock was supplied by two Grason-Stadler 900 series shock generators and auxiliary scramblers. Settings on the shockers were adjusted to provide $.5-\mathrm{mA} .5-\mathrm{sec}$ shock to each unit. All other events were programmed and recorded automatically by a series of electromechanical suitching circuits, timers, counters, and cumulative recorders. White noise, approximately $78 \mathrm{~dB}$, was continuously present to further attenuate any extraneous noises.

\section{Procedure}

Ss were deprived of water for $48 \mathrm{~h}$, shaped to barpress for water. and then given three $1 / 2$-h daily sessions of CRF in order to raise the probability of the desired operant.

Following initial leverpress training, Ss were given training in a discriminative barpress avoidance task. Animals were required to respond during a $15-\mathrm{sec} C S$ in order to (1) terminate CS and (2) prevent the LS programmed for that trial. If a response failed to occur during the CS. shock was presented simultaneously with CS termination. No opportunity for escape was possible. Each training session consisted of 200 avoidance trials (approximately $1 \mathrm{~h}$ and $45 \mathrm{~min}$ ). Interstimulus intervals and intertrial intervals were $15 \mathrm{sec}$ and $30 \mathrm{sec}$. respectively. Ss were exposed to the avoidance contingencies until their records indicated better than $50^{\circ} \mathrm{c}$ avoidance for the last 100 trials on a given day.

\section{Extinction}

As an animal attained the avoidance criterion. ${ }^{1}$ it was randomly assigned to one of three extinction conditions. The three conditions varied according to the presence and pattern of US presentations.

On the first extinction day following criterion. Ss were given 100 avoidance trials followed immediately by 100 extinction trials. On Days 2-6. Ss were exposed to 200 extinction trials per session. Extinction consisted of the following: Group I (VR) was given shocks according to a $50 \%$ random reinforcement schedule. i.e.. shocks followed a random half of the CS presentations. A response during CS could neither terminate CS nor prevent shock if it was programmed for that trial. Group II (OE) was given $100 \%$ CS-US pairings throughout the extinction series. Group III (CE) was never presented with any shocks but was given CS-only trials throughout the extinction series. Thus, under all conditions, CS termination and LS occurrence were independent of the S's behavior.

\section{Relearning}

Following the extinction series, the original avoidance contingencies were reinstated. A maximum of 1000 reconditioning trials across 5 days were given and avoidance rates were recorded. However, if a $S$ reached $50^{\circ} c$ avoidance or better during the last 100 trials of a given day. it was terminated and its final rate was incorporated in the group data for the remaining sessions.

\section{RESULTS}

\section{Acquisition}

Although 32 Ss were initially exposed to the avoidance contingencies, only 17 animals ever achieved criterion and 2 were deleted due to $\mathrm{E}$ error during the course of the study. No differences in terminal avoidance rates were obtained between the three groups prior to the start of extinction $(F<1.00)$.

\section{Extinction}

The data clearly revealed greatest resistance to extinction for the VR Ss, with extinction occurring most rapidly under $C E$ conditions. A Treatment by 25 Trial Blocks analysis of variance on the extinction data revealed a significant effect of treatment $(F=14.45$. $\mathrm{df}=2 / 12, \mathrm{p}<.001)$ and blocks $(\mathrm{F}=14.90 . \mathrm{df}=43 / 516$. $\mathrm{p}<.001$ ), but no significant Treatment by Blocks interaction $(F=1.23, \mathrm{df}=86 / 516, \mathrm{p}>.05)$.

The left-hand portion of Fig. 1 depicts the group data in blocks of 100 trials. It can be seen that responding dropped out during the first 100 trials in the CE Ss and was maintained at a minimal level throughout the remainder of the extinction series. The behavior of the VR Ss showed prolonged resistance to extinction. with greater day to day variability than either the $\mathrm{CE}$ or $\mathrm{OE}$ Ss. The average responses for the VR Ss stayed above that of the OE Ss through the first 700 trials of 
extinction. A Neuman-Keuls test for ordered differences (Winer, 1962) among treatment means during experimental extinction revealed significant differences $(p<.01)$ for all comparisons. The average number of responses per block during extinction was 14.9 for the VR group, 8.4 for the OE group, and 4.6 for the $\mathrm{CE}$ group.

Figure 2 shows the response patterns for two typical Ss in each group during the first 2 days of extinction. Extinction began following 100 avoidance trials. Notice that the response rates for the VR Ss show no discriminable decrease in slope even after 300 trials. Their response patterns are indistinguishable from the behavior during terminal avoidance. In contrast, the behavior of the OE Ss shows an immediate decline at the start of extinction which continues (especially in S 22) on the second day. The rates for the CE Ss show marked attenuation of responding to a very low near-zero level by the second day.

\section{Relearning}

The use of a Treatment by Blocks analysis on the relearning data was discarded, since at criterion $(50 \%$ avoidance) the $\mathrm{S}$ was terminated. Had such an analysis been employed, the within-groups variability would be spuriously lowered: thus, a one-way analysis was employed to insure information on each $\mathrm{S}$. The analysis conducted across extinction groups, using the percent avoidance for Relearning Trials 201-300, revealed a significant effect of treatment $(F=98.64, \mathrm{df}=2 / 12$, $\mathrm{p}<.001)$.

The right portion of Fig. 1 clearly shows that all $\mathrm{CE}$ Ss reached criterion by the second day (Block 4) and four of these Ss had achieved criterion on the first day. Four of the five Ss in the VR group, but only two of five Ss in the OE group, ever achieved $50 \%$ avoidance within the limits of the experiment.

\section{DISCUSSION}

The extinction data clearly support a discriminative interpretation of avoidance extinction and, thus, extend the applicability of the discrimination hypothesis to

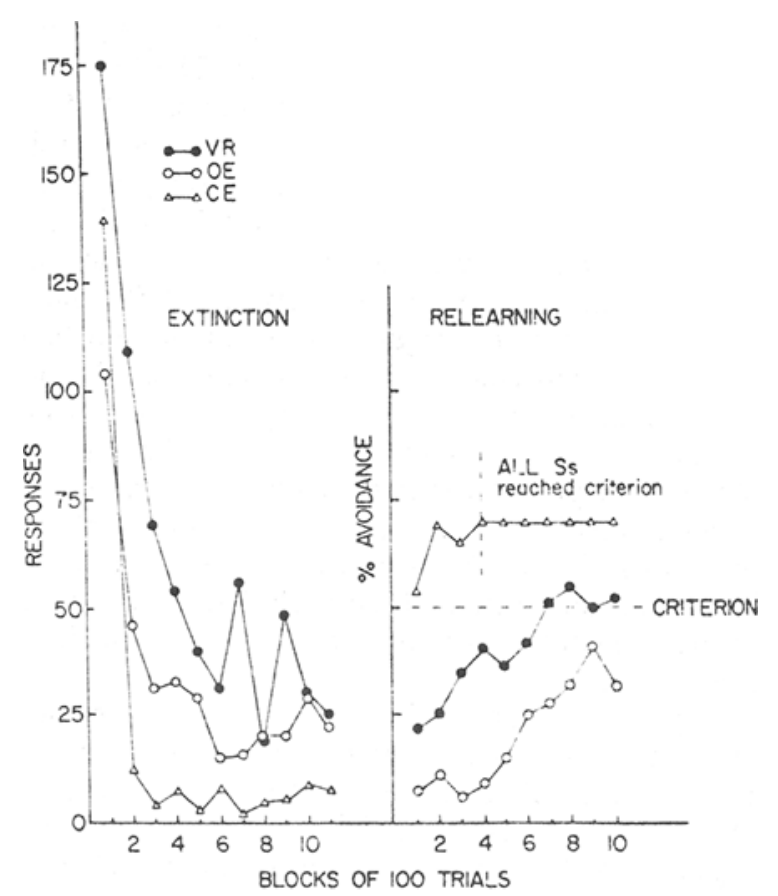

Fig. 1. Mean number of responses in extinction and mean avoidance rate during reacquisition for each experimental group.

situations involving aversive contingencies. Greatest resistance to extinction of avoidance was obtained with variable-ratio shock, a condition which most clearly matched shock density in extinction with that occurring during terminal acquisition. In contrast, extinction occurred most rapidly under CE conditions, a situation in which all cues signaling avoidance were removed. These cues included the presence of shocks in addition to response-contingent termination of the $\mathrm{CS}$. Under $\mathrm{OE}$ conditions, shocks persist, informing the $S$ it is still in an avoidance situation, but responses are no longer effective in precluding shock occurrence.

Although the findings of previous investigations requiring similar response requirements, i.e. leverpressing to avoid shock, are consonant with a discriminative interpretation of the data, they did not provide appropriate comparisons necessary to rule out a motivational analysis. These studies compared only two

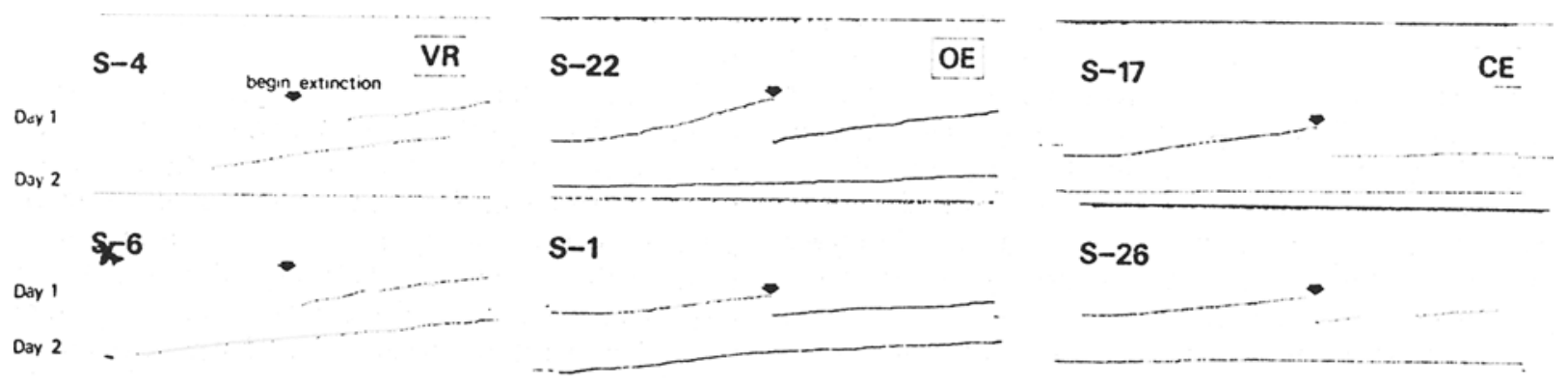

Fig. 2. Cumulative response records for two typical Ss in each group across the first 2 days of experimental extinction. Each session is $1 \mathrm{~h}$ and $45 \mathrm{~min}$. 
procedures. CE with either OE (Jackson \& Scheuer. 1972) or VR (Coulson et al. 1970). The latter study found greater resistance to extinction of Sidman avoidance under "playback" shock vs no-shock conditions. while Jackson and Scheuer found faster extinction under $C E$ as compared to $\mathrm{OE}$ conditions in a paradigm similar to that used in the present study. Since only a direct comparison between $V R$ and $O E$ conditions would require differential predictions regarding resistance to extinction based on a motivational or discriminative interpretation, motivation theory could have as easily predicted the differences obtained in previous studies. With data derived from a direct comparison of all three procedures as employed in the present study, a motivational interpretation is no longer feasible, since such an analysis would necessarily predict greatest resistance to extinction under $\mathrm{OE}$ contingencies.

It might be argued. however. that the presence of shock is not necessarily serving a discriminative function but is rather maintaining a high level of general activity. There are two reasons for rejecting such an alternative explanation. First. we have been unable to achieve any' responding whatsoever without both preshaping for positive reinforcement and moving the $\mathrm{CS}$ to a position away from the response lever. That is, shocks per se do not tend to facilitate barpressing but, instead. probably promote other defense behaviors, such as freezing, rearing, and turning. that are generally incompatible with the required operant. Second, if shocks were serving an activating function during extinction, the response rates for the OE Ss should have been higher than those for the VR Ss, since their relative shock rates were twice as great.

In addition to explaining resistance to extinction involving aversive contingencies, the discriminative interpretation also accounts for the extinction data obtained by Rescorla and Skucy (1969) in appetitive situations. They found that providing food on a variable-interval schedule independently of the S's behavior produced greater resistance to extinction than the traditional one calling for the elimination of food. Their VI free-food condition more closely resembled conditions occurring during preextinction conditions, the only major change being disruption of the response-reinforcement contingency.

The present design merely tested the relative merits of a discriminative vs motivational interpretation of avoidance extinction. The discrimination hypothesis does not specify what constitutes a major change from acquisition. It is our contention that. not only is the response-reinforcement relationship a critical alteration, but also the discriminative properties of the reinforcing stimuli are of major significance in prolonging extinction of a conditioned operant.

The present results contrast. however. with those studies requiring behavior involving species-specific defense reactions such as running or shuttling in a one-way avoidance task (Bolles. Moot.\& Grossen. 1971: Bolles. 1971). These investigators found greater resistance to extinction under $\mathrm{CE}$ as compared to $\mathrm{OE}$ conditions. It must be remembered, however. that other discriminable events (e.g.. place and response-produced cues) relevant to one-way avoidance do not apply to barpress avoidance and their contribution to response maintenance cannot be adequately assessed.

To summarize the extinction data, the relative rates of extinction of each of the groups in the present study clearly support a discriminative rather than a motivational interpretation. Further research extending this work to two-way shuttlebox avoidance is currently underway. Like the operant box, a two-way running response minimizes the contribution of place along with response-produced cues to maintenance of avoidance behavior. It would also be interesting to determine whether "playback" shock produces comparable rates of extinction regardless of the rate of initial avoidance. According to a discriminative interpretation. no differences in extinction should be obtained if Ss receive the same pattern of shocks in acquisition and extinction. regardless of the particular schedule employed.

The relearning data, in contrast to the extinction data. cannot be adequately explained by either discrimination or motivational theory. Under a discriminative interpretation. one would predict faster relearning for the CE group and slower relearning under VR conditions. Motivational theory would predict the opposite rates of reacquisition of those obtained in the present study.

An alternative explanation of the relearning rates is suggested, one which relates to the frequency and consistency of exposure to uncontrollable events or. in other words. to the acquisition of "learned helplessness" (Seligman. Maier, \& Solomon, 1971). The relative rates of reacquisition for the three groups clearly point to the fact that the fewer the number of exposures to response-independent CS-US pairings, the faster is the rate of reacquisition. The rate of relearning after no-shock extinction was very rapid. and all CE Ss regained criterion performance within 400 trials. This was not the case for the OE Ss. who were exposed to 1100 trials in which the CS consistently predicted US occurrence and all responses were ineffective in precluding shock. Only two animals exposed to the $\mathrm{OE}$ procedure relearned the avoidance response within 1000 trials.

Seligman, Maier. and Solomon have suggested. however. that animals may be immunized against learned helplessness by prior exposure to escape or avoidance training. Although $S s$ in the present study were given prior avoidance training. reacquisition was prevented in three of the five OE Ss. Their suggestion is that a prior history of a well-learned escape or avoidance response will enhance future escape or avoidance behavior. even after a history of uncontrollable events. It is unclear. however. as to what is meant b! well learned. and some 
suther have found that if an ammal is only tratled to wheve partial control wer shocks (as in the present deign). uncontrollable shocks will interfere with whseyuent learning in future response-contingent avoidance tasks (Anderson, Rollins. \& Rishkin. 1966). This pussibility is supported by the different terminal icquisition levels achieved by the OE Ss who relearned the aroidance task as compared to Ss who showed learned helplessness. The first OE animal to achieve criterion during relearning was performing at $71 \%$ avoidance prior to extinction, while the other was avoiding at $60 \%$. The three $\mathrm{OE}$ animals that failed to relearn were performing at only $51 \%, 52 \%$. and $58 \%$ avoidance prior to the start of extinction. It is possible that some critical avoidance rate must be attained to prevent exposure to uncontrollable aversive events from producing learned helplessness.

The intermediate level of performance of the VR Ss might have resulted from partial exposure to learned helplessness trials. That is, at times $R_{A} v$ might have adventitiously prevented shock if shock was not programmed for that trial. Superstitious reinforcement of this type might have retarded the acquisition of learned helplessness in some of the VR Ss. This interpretation seems particularly appealing, since only one animal in the VR condition failed to reacquire the avoidance response to criterion within the limits of the experiment. Their rates of relearning, however, were much poorer than those of the CE Ss.

In conclusion, the data clearly support a discriminative interpretation regarding resistance to extinction of barpress avoidance. The more similar acquisition conditions are to the extinction contingencies, the greater will be resistance to extinction. The relearning data seem to point to a learned helplessness interpretation. It is suggested that some critical avoidance criterion must be attained prior to exposure to response-independent CS-US pairings for immunization procedures to be effective.

\section{REFERENCES}

Anderson. N. H., Rollins. H. A., \& Rishkin. S. R. Iffects of punishment on avoidance decrement. Journal of Comparative \& Physjological Psychology. 1966. 62. 147-149.
Bolles. R. C. Species-specific defense reactions. In I. R. Brush II d.I. Alersilo conditioning and learning. Noll York: Academic Press. 1971. Pp. 183-234.

Bolles. R. C.. Moot. S. A.. \& Grossen. X. E. The extinction of shuttlebox avoidance. Learning \& Motivation. 1971. 2. 324-333.

Coulion. G.. Coutson. V.. \& Gardner. L. The effect of two extinction procedures after acquisition on a Sidman avoidance contingency. Psychonomic Science. 1970. 18. 309.310.

D'Amato. II. R.. \& Fazzaro. J. Discriminated lever-press avoidance learning as a function of type and intensity of shock. Journal of Comparative \& Physjological Psychology'. 1966. 61. 313-315

Davenport, D. G. \& Olsen. R. D. A reinterpretation of extinction in discriminated avoidance. Psychonomic Science. $1968,13,5-6$

Jackson, M. C., \& Scheuer. C. A comparison of two procedures for breaking the response-reinforcement contingency in discriminated barpress avoidance. Psychonomic Science. 1972, 29. $14 \cdot 16$

Lewis. D. J. Partial reinforcement: A selective review of the literature since 1950. Psychological Bulletin. 1960, 57. 1-28.

Nower. O. H., \& Jones, H. M. Habit strength as a function of the pattern of reinforcement. Journal of Experimental Psychology, 1945, 35, 293-311.

Rescorla. R. A., \& Skucy, J. C. Effect of response-independent reinforcers during extinction. Journal of Comparative \& Physiological Psychology, 1969.67, 381-389.

Seligman. M. E. P.. Maier. S. F ., \& Solomon, R. L. Unpredictable and uncontrollable aversive events. In F. R. Brush (Ed.), Alersive conditioning and learning. New York: Academic Press. 1971. Pp. 347-401

Hiner. B. J. Statistical principles in experimental design. New York: McGraw-Hill. 1962.

\section{NOTE}

1. The avoidance iriterion used in the present study might appear rather low relative to other avoidance behaviors. such as a one-w ay running response that typically achieves 100, within a few hundred trials. However. when comparing this criterion with the levels reported by other investigators utilizing arbitrary avoidance behaviors and moderate shock intensities (D'A mato \& Fazzaro, 1966: Bolles, 19711. our animals fare rather well. Certainly. the use of such a response. at present. limits the gencrality of the data regarding other avoidance behaviors. such as SSDRs. Our initial concem, however. was to determine the relative extinction rates of a behavior that was as free as possible from classically conditioned components.

(Received for publication February 1. 1973: revision received March 20.1973.1 